\title{
Genetic Relationship in Tea Germplasms with Drought Contrasting Traits
}

\author{
Sagarika Das ${ }^{1 \dagger}$, Afruza $\operatorname{Zaman}^{1 \dagger}$, Sangeeta Borchetia ${ }^{1} *$, Madhurjya Gogoi ${ }^{1}$, Pritom Chowdhury ${ }^{1}$, Jayanta Saikia ${ }^{2}$, \\ Hemanta Saikia', Buddhadeb Das', Tarun Sen Barman², Tanoy Bandyopadhyay ${ }^{1}$ \\ ${ }^{1}$ Department of Biotechnology, ${ }^{2}$ Department of Plant Physiology and Breeding, Tea Research Association, Tocklai Tea Research \\ Institute, Jorhat-785008, India
}

\begin{abstract}
The objective of this study is to correlate the genetic diversity among tea cultivars with drought tolerance/susceptibility on the basis of morphological, physiological and molecular markers. Twelve highly polymorphic inter simple sequence repeat primers targeting the tea dinucleotide repeats predominantly present in drought stressed transcripts were used to screen out the germplasms into two groups showing drought tolerance and susceptible characteristic with polymorphic information content of 0.3 . A similarity index of 0.58 was observed among the cultivars. Morpho-physiological diversity among the cultivars was studied using eighteen morphological and two physiological markers. Correlation studies showed significant association between the ranks of the morpho-physiological distances and molecular genetic distances at $\mathrm{P}=0.05 \%$. The dinucleotide repeats targeted along with morpho-physiological correlation can be used in tea breeding for drought tolerance as the markers are in sync with the long term field trials based on which the plants were classified for drought trait.
\end{abstract}

Keywords Tea, Morpho-physiological markers, ISSR, Drought tolerance, Correlation

\section{INTRODUCTION}

Drought stress stimulates a broad response in tea plant, Camellia sinensis (L.) O. Kuntze, which changes the cellular metabolism and ultimately affects growth and yield. As tea plant is highly heterogenous, natural hybridization results in significant genetic variation (Panda 2011). Several tea genotypes are known for their tolerance and susceptibility to drought based on physiological traits (Barman et al. 2008) and extensive field trials (Singh 2006). But the genetic relationships amongst these varieties are still unknown, which knowledge will enable to correlate the traits with markers for using in conventional tea breeding programmes. Adaptability of tea plants to various stresses with inherent quality for the end product is a determining factor in large plantations. Selected markers should be able to discriminate between drought tolerant and susceptible cultivars using rapid and inexpensive methods. Generally shoot and leaf characteristics are the easiest morphological traitstable to select tea varieties under field conditions. Morphological descriptors were the earliest markers used in germplasm conservation but have limitations like low polymorphism, low heritability, late expression and vulnerability to environmental stresses (Smith and Smith 1992). Physiological parameters like changes in turgor, osmotic pressure, leaf water potential, stomatal conductance and transpiration (Ribas-Carbo et al. 2005), low leaf growth rate, high water use efficiency (WEU), proline, abscisic acid are useful indicators for drought tolerance. Phenotypic markers in association with

Received September 2, 2016; Revised November 17, 2016; Accepted November 18, 2016; Published November 30, 2016

*Corresponding author Sangeeta Borchetia, sborchetia7@gmail.com, Tel: +91-376-2360973, Fax: +91-376-2360474

${ }^{\dagger}$ These authors contributed equally to this paper as co-first authors. 
molecular markers can accelerate tea plant breeding efforts and selection of improved tea varieties with better stress tolerance. The effectiveness of both morphological and physiological markers varies with growth stages of the tea plant as well as environmental conditions. Molecular markers however do not vary at different conditions and may help to identify some particular stress tolerant traits that may be possessed by a plant variety at the genetic level. Inter simple sequence repeats (ISSR), regions between adjacent microsatellites, is a useful marker for the study of genetic diversity and phylogeny (Tomar et al. 2010). ISSR markers based on AG and GA repeats have been reported to be very informative in rice (Sarla et al. 2003) and wheat (Deshmukh et al. 2012) for drought tolerance. The drought expressed sequence tags of tea also represented high frequency of AG, GA, TC, CT repeats (Gogoi et al. 2014). In this study we have used these repeats sequence to generate ISSR primers to correlate molecular polymorphism with morpho-physiological traits of tea plants for developing an effective approach for selection of drought tolerant varieties which generally may take 10 years through conventional breeding.

\section{MATERIALS AND METHODS}

\section{Plant material}

Thirteen drought tolerant and eleven drought susceptible cultivars of cultivated tea (Table 1) were selected based on long term field trials under different agroclimatic conditions for their drought trait (Barman 2011). The leaf samples of these cultivars were collected from the germplasm conservation site of Tocklai Tea Research Institute, Jorhat, Assam for the experiments. The physiological and the morphological data were generated from the plants in the field conditions during the winter season (January and February) when rainfall was minimum in Assam (Supplementary Table 1).

Table 1. Description of different cultivars used in the study.

\begin{tabular}{|c|c|c|c|c|}
\hline Serial No. & Cultivar name & Cultivar ID & $\begin{array}{l}\text { Drought tolerant (DT)/ } \\
\text { drought susceptible (DS) based on field study }\end{array}$ & $\begin{array}{l}\text { Age of the plant } \\
(\mathrm{yr})\end{array}$ \\
\hline 1 & Dhul41 & $\mathrm{T} 1$ & DT & 19 \\
\hline 2 & BJ19 & $\mathrm{T} 2$ & DT & 19 \\
\hline 3 & Lengree56 & $\mathrm{T} 3$ & DT & 12 \\
\hline 4 & Lengree 51 & $\mathrm{~T} 4$ & DT & 12 \\
\hline 5 & GP-19 & $\mathrm{T} 5$ & DT & 26 \\
\hline 6 & TV -25 & T6 & DT & 43 \\
\hline 7 & TV -23 & $\mathrm{~T} 7$ & DT & 44 \\
\hline 8 & TV-26 & $\mathrm{T} 8$ & DT & 43 \\
\hline 9 & TV-1 & T9 & DT & 44 \\
\hline 10 & TV-20 & $\mathrm{T} 10$ & DT & 44 \\
\hline 11 & TV-19 & $\mathrm{T} 11$ & DT & 44 \\
\hline 12 & TV-17 & $\mathrm{T} 12$ & DT & 44 \\
\hline 13 & $\mathrm{CP}-1$ & $\mathrm{~T} 13$ & DT & 22 \\
\hline 14 & TV-2 & $\mathrm{T} 14$ & DS & 44 \\
\hline 15 & TV-4 & $\mathrm{T} 15$ & DS & 44 \\
\hline 16 & TV-6 & $\mathrm{T} 16$ & DS & 44 \\
\hline 17 & TV-8 & $\mathrm{T} 17$ & DS & 44 \\
\hline 18 & TV -13 & $\mathrm{~T} 18$ & DS & 44 \\
\hline 19 & TV -15 & $\mathrm{~T} 19$ & DS & 44 \\
\hline 20 & TV-21 & $\mathrm{T} 20$ & DS & 44 \\
\hline 21 & Borsillah 24 & $\mathrm{~T} 21$ & DS & 19 \\
\hline 22 & Baghmari 20 & $\mathrm{~T} 22$ & DS & 19 \\
\hline 23 & Baghmari 35 & $\mathrm{~T} 23$ & DS & 19 \\
\hline 24 & Gohpur33 & $\mathrm{T} 24$ & DS & 21 \\
\hline
\end{tabular}




\section{Morpho-physiological study}

Twenty three morphological characters of the cultivars (Supplementary Table 2) were analysed qualitatively and quantitatively following the guidelines of International Plant Genetic Resources Institute (IPGRI 1997). For each morphological character mean of ten replicates were considered. Plant physiological parameters such as photosynthesis, transpiration rate, WUE were determined by using Infrared Gas Analyzer (Ciras II, PP system; Stortfield, Hitchin Herts, UK). Leaf wax content was determined according to Silva Fernandes et al. (1964).

\section{Extraction of DNA and ISSR amplification}

Genomic DNA was extracted using the methodology of Doyle and Doyle (1987) with slight modifications. The quality and quantity of the extracted DNA was checked using a spectrophotometer (Eppendorf) to get a concentration of $50 \mathrm{ng} / \mu \mathrm{l}$ for further downstream processes. ISSR region in the genomic DNA was amplified using 12 primers representing the dinucleotides (TC, AG, GA, CT, $\mathrm{CA}$, and $\mathrm{AC}$ ) (Fig. 1). Polymerase chain reaction reactions were carried out in $10 \mu \mathrm{l}$ volume containing $50 \mathrm{ng}$ of total DNA, 1X Taq Buffer B (Genei), $1.25 \mathrm{mM} \mathrm{MgCl}_{2}, 0.5 \mathrm{mM}$ dNTPs, $0.5 \mathrm{mM}$ primer and $0.1 \mathrm{U}$ Taq DNA polymerase in a programmable Veriti (Applied Biosystems, Foster City, CA, USA) thermocycler. The amplification protocol includes initial denaturation at $94^{\circ} \mathrm{C}$ for 5 minutes followed by 40 successive cycles of denaturation at $94^{\circ} \mathrm{C}$ for 30 seconds, primer annealing at respective $\mathrm{Tm}$ values (ranging from $40^{\circ} \mathrm{C}$ to $55^{\circ} \mathrm{C}$ ) for the selected primers for 30 seconds and extension at $72^{\circ} \mathrm{C}$ for 2 minutes. This was followed by a final extension at $72^{\circ} \mathrm{C}$ for 10 minutes. The amplicons were then separated in $1 \%$ agarose gels, visualized under ultraviolet light and documented in a Protein Simple AlphaImager MINI gel documentation system (Cell Biosciences Inc., Santa Clara, CA, USA).

\section{Statistical analysis}

The capacity of the ISSR primers to distinguish among the genotypes studied was evaluated by gene diversity and the polymorphic information content (PIC) using the genetic analysis package Power Marker (ver. 3.23; Liu and Muse 2005). Since the ISSR markers are dominant it was assumed that each band represent the phenotype at a single bi-allelic locus. The ISSR markers were scored into a binomial matrix (0/1) and similarities among the loci were calculated by Jaccard's coefficient. The similarity matrix was used to input data for cluster analysis by applying unweighted pair group method with arithmetic averages (UPGMA) and a tree plot was drawn using NTSYS-pc (version 2.11X).

Principal component analyses of morphological and physiological data were done based on pearson correlation coefficient using XLSTAT 14.5.4 software. For morphological data like mature leaf shape, leaf blade habit, leaf base shape etc, the variations were coded into numerical values like 1, 2, 3 etc and analysed. Two level analysis of

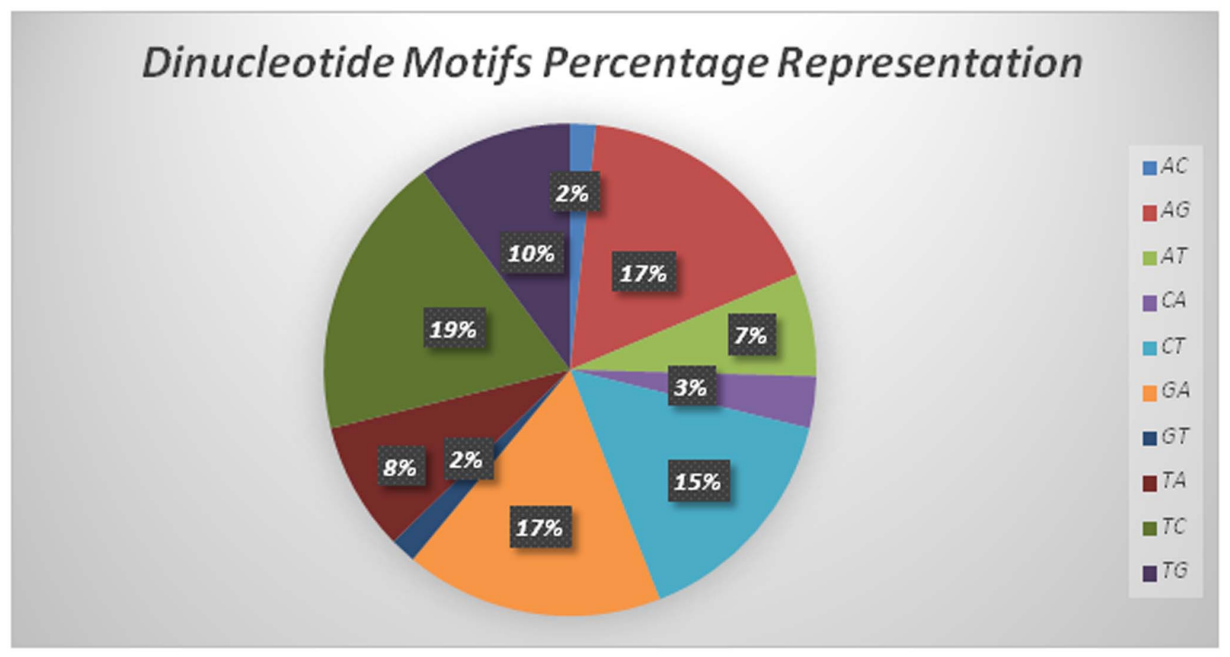

Fig. 1. Dinucleotide motif representation in drought tea EST library. 
variance was performed on the quantitative morphological and physiological data to find the significant variables between the drought tolerant and susceptible cultivars. Tukey honest significant difference post-hoc test was done to determine the differences between the groups at $95 \%$ confidence interval. The morpho-physiological traits showing significant differences between drought tolerant and susceptible varieties are only taken for mantel test to study the correlation between morpho-physiological matrix and molecular matrix at $0.05 \%$ significance level using one tailed test in XLSTAT 14.5.4 software.

\section{RESULTS}

\section{Diversity based on morpho-physiological traits}

Plants develop various morphological traits to adapt in stressful environments. Twenty three morphological traits were studied to differentiate the selected cultivars on drought tolerance or susceptibility (Supplementary Table 2). Five traits namely growth habit, stem type, leaf apex shape, leaf surface waxiness and pigmentation in young leaves and petiole were not informative and eliminated. The remaining traits were analyzed and found that leaf surface area, pubescence and leaf angle although showed differences in the contrasting cultivars, they were not significantly distinguishable for the drought traits in the cultivars studied (Table 2). The average leaf surface area of the drought tolerant plants $\left(73.05 \mathrm{~cm}^{2}\right)$ was found to be less than the drought susceptible plants $\left(74.36 \mathrm{~cm}^{2}\right)$ (Supplementary Table 2, Sheet 2). The average branch angle was higher in drought susceptible cultivars $\left(47.38^{\circ}\right)$ than the tolerant cultivars $\left(43.95^{\circ}\right)$ (Supplementary Table 2 , Sheet 2). Light intensity and photosynthetic rate was not significant between the two contrasting traits (Fig. 2). However, transpiration loss, WUE and cuticular wax was significant at $P<0.05$ (Table 2). Only the highly informative characters consisting of 18 morphological parameters and two physiological parameters (WUE and cuticular wax) were considered in the morpho-physiological correlation studies. Principal component analysis to determine the association of only the morphophysiological

Table 2. Individual ANOVA of measured morphophysiological variables.

\begin{tabular}{|c|c|c|c|c|c|c|c|c|}
\hline Variable & $\begin{array}{l}\text { Source of } \\
\text { variation }\end{array}$ & $\begin{array}{l}\text { Sums of } \\
\text { squares }\end{array}$ & $\mathrm{Df}^{\mathrm{z})}$ & Variance & $\mathrm{F}$ & $95 \% \mathrm{CI}$ & $P$-value & Sig \\
\hline \multirow[t]{2}{*}{ Light intensity } & Between groups & $8,147.7$ & 1 & $8,147.70$ & 0.359 & $(-164.8-90.93)$ & 0.5550 & NS \\
\hline & Within groups & $498,711.05$ & 22 & $22,668.68$ & & & & \\
\hline \multirow{2}{*}{$\begin{array}{l}\text { Transpiration } \\
\text { loss }\end{array}$} & Between groups & 10.746 & 1 & 10.746 & 5.871 & $(0.193--2.492)$ & 0.0241 & $*$ \\
\hline & Within groups & 40.268 & 22 & 1.8304 & & & & \\
\hline \multirow{2}{*}{$\begin{array}{l}\text { Photosynthetic } \\
\text { rate }\end{array}$} & Between groups & 1.0511 & 1 & 1.0511 & 0.208 & $(-2.32--1.489)$ & 0.6528 & NS \\
\hline & Within groups & 111.16 & 22 & 5.0531 & & & & \\
\hline \multirow{2}{*}{$\begin{array}{l}\text { Water use } \\
\text { efficiency }\end{array}$} & Between groups & 0.4028 & 1 & 0.4028 & 5.137 & $(0.497--0.022)$ & 0.0336 & $*$ \\
\hline & Within groups & 1.7248 & 22 & 0.0784 & & & & \\
\hline \multirow[t]{2}{*}{ Cuticular wax } & Between groups & $2,148.69$ & 1 & $2,148.69$ & 5.167 & $(-36.31--1.66)$ & 0.0331 & $*$ \\
\hline & Within groups & $9,147.82$ & 22 & 415.81 & & & & \\
\hline \multirow[t]{2}{*}{ Branch angle } & Between groups & 70.099 & 1 & 70.0992 & 2.456 & $(-1.108-7.968)$ & 0.1313 & NS \\
\hline & Within groups & 627.69 & 22 & 28.5317 & & & & \\
\hline \multirow{2}{*}{$\begin{array}{l}\text { Length of } \\
\text { mature leaf }\end{array}$} & Between groups & 0.0024 & 1 & 0.0024 & 0.001 & $(-1.33-1.291)$ & 0.9751 & NS \\
\hline & Within groups & 52.426 & 22 & 2.3830 & & & & \\
\hline \multirow{2}{*}{$\begin{array}{l}\text { Width of } \\
\text { mature leaf }\end{array}$} & Between groups & 0.0381 & 1 & 0.0381 & 0.064 & $(-0.573-0.733)$ & 0.8018 & NS \\
\hline & Within groups & 12.999 & 22 & 0.5909 & & & & \\
\hline \multirow[t]{2}{*}{ Leaf pose } & Between groups & 4.7196 & 1 & 4.7196 & 0.150 & $(-5.642-3.862)$ & 0.7015 & NS \\
\hline & Within groups & 688.399 & 22 & 31.2909 & & & & \\
\hline \multirow{2}{*}{$\begin{array}{l}\text { Length of mature } \\
\text { leaf petiole }\end{array}$} & Between groups & 0.0149 & 1 & 0.0149 & 1.65 & $(0.1306-0.030)$ & 0.2114 & NS \\
\hline & Within groups & 0.1978 & 22 & 0.0090 & & & & \\
\hline
\end{tabular}

${ }^{z)}$ Df: degrees of freedom, CI: confidence interval, Sig: significance level $(P<0.05)$, NS: not significant. 

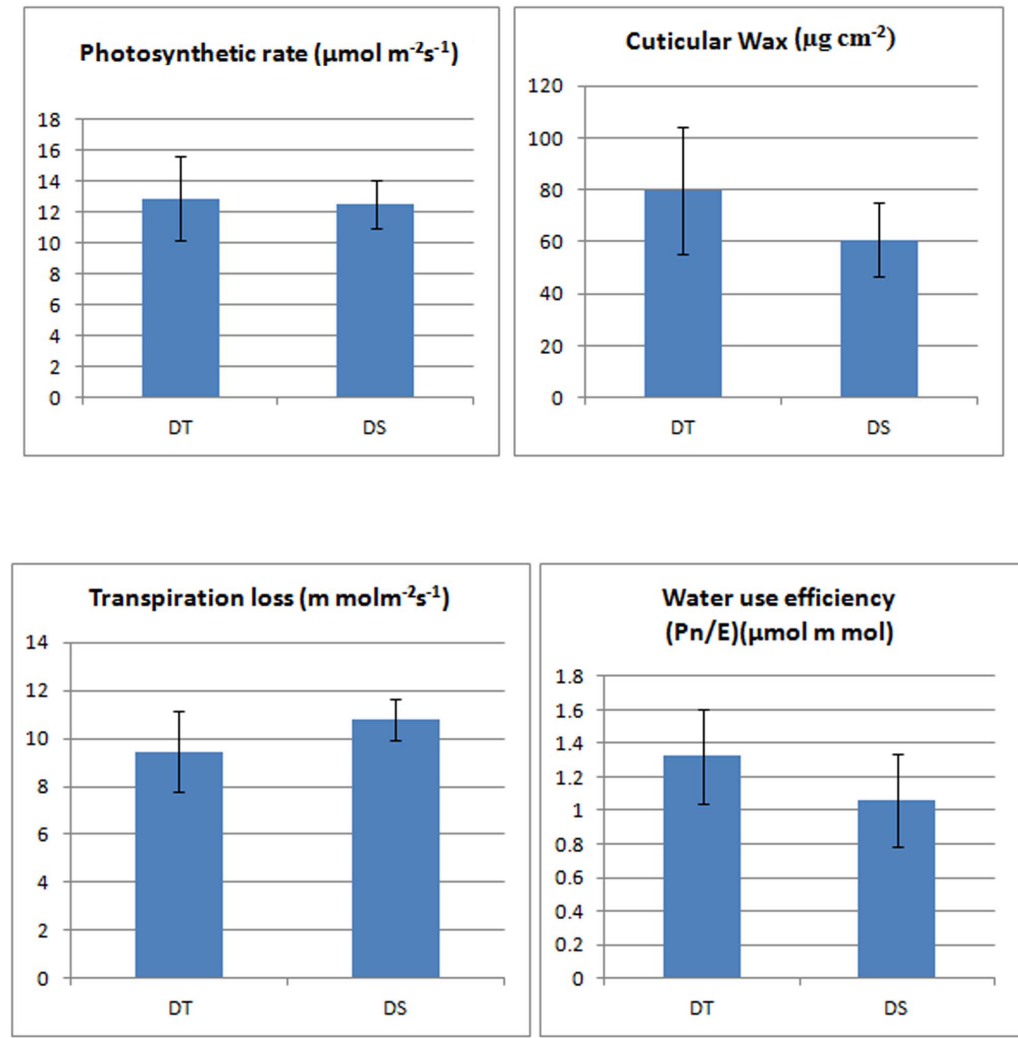

Fig. 2. Graph representing the physiological parameters shown by drought tolerant (DT) and drought susceptible (DS) cultivars.

characters to tea varieties revealed that the drought tolerant clones Len 51, Len 56, TV26, TV25, TV19, GP 19 showed differences for leaf apex habit, pubescence, length of the mature leaf, leaf petiole, leaf colour, petiole colour and WUE (Fig. 3). However, distinct clustering into two separate groups consisting of drought tolerant and susceptible cultivars were not observed with the 20 morpho-physiological characters studied. Clone CP1 and Dhul 41 showed close clustering and were found to be distant from rest of the germplasms.

\section{Genetic diversity using ISSR markers targeting dinucleotide repeats}

Tea drought transcripts were mostly represented by TC (19\%), GA (17\%), AG (17\%), and CT (15\%) repeats. AC (2\%) repeats showed lowest representation in the tea drought EST library (NCBI accession no. HS393200 HS396831). The inter region within these repeats were targeted to classify the drought tolerant and susceptible

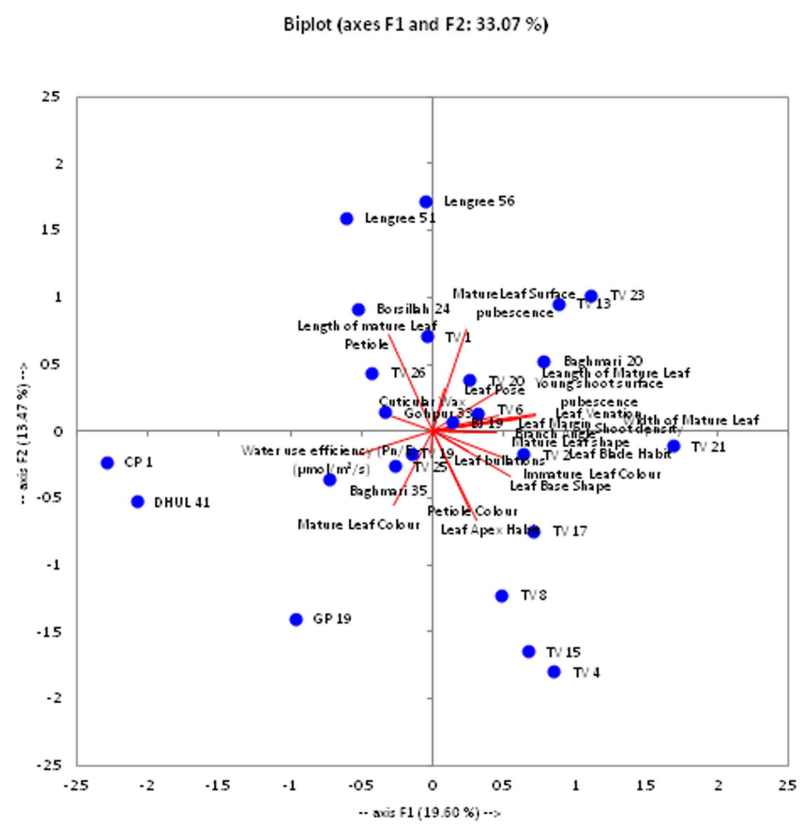

Fig. 3. Principal component analysis of morpho-physiological data. The percentages of variation described by the factorial axes (F1 and F2) are given in paranthesis. 
germplasms with random anchoring of one to three nucleotides at the 3 '. The 12 ISSR primers produced a total number of 159 bands ranging from $150 \mathrm{bp}$ to $1,600 \mathrm{bp}$ in the 24 germplasms with a percentage polymorphism ranging from $72.7 \%$ to $100 \%$ (Table 3 ). The 12 primers showed differences in polymorphism profiles among drought tolerant and drought susceptible varieties (Fig. 4). The mean polymorphism percentage was 96.54 and the mean polymorphism information content is 0.3 which is highly informative for the ISSR makers used.

UPGMA clustering identified two clusters consisting of drought tolerant and drought susceptible genotypes at a similarity index of 0.58 (Fig. 5). Within cluster 1, BJ19 and Lengree 51 sharing a similarity index of 0.92 showed approximately $90 \%$ similarity with Lengree 56 . TV 23 and TV25, both highly drought tolerant cultivars showed $84 \%$ similarity with each other and shared a $74 \%$ similarity with other drought tolerant clones. TV1 clustered with the drought tolerant clones at a similarity index of approximately $70 \%$ and was the most distant among the drought tolerant cultivars studied. Within cluster 2, the drought susceptible cultivars separated into two groups, at a similarity index of about 0.73 . The drought susceptible genotypes TV4, TV8, TV6, TV13, TV15, TV2, TV21 grouping under one cluster showing high similarity originates from a similar gene pool of Assam Jats (source from where the seeds are originally obtained).

\section{Correlation between morpho-physiological and molecular markers}

Mantel's correlation studies based on the ranks of morpho-physiological distances determined from the pearson correlation matrix of 20 morpho-physiological traits showed significant correlation with the ranks of molecular distances determined from the pearson correlation matrix of the 12 ISSR markers (Supplementary Table 3). The rank correlation value (r) was 0.158 at the level of $0.05 \%$ significance level (Fig. 6). This result indicates that the ranking of divergence between the tea genotypes based on morpho-physiological data has correlation with molecular data.

\section{DISCUSSION}

The correlation between morpho-physiological traits and ISSR markers targeting few dinucleotide repeats in drought stress transcripts were studied in 24 tea cultivars. Selection and development of a new tea cultivar requires nearly 7 to 10 years. So, breeding with the assistance of

Table 3. Attributes of ISSR primers in generating PIC.

\begin{tabular}{|c|c|c|c|c|c|c|c|c|}
\hline \multirow{2}{*}{ Code No. } & \multirow{2}{*}{ ISSR $^{\mathrm{z})}$ primer } & \multicolumn{2}{|c|}{ Allele size (bp) } & \multirow{2}{*}{ NTL } & \multirow{2}{*}{ NML } & \multirow{2}{*}{ NPL } & \multirow{2}{*}{$\mathrm{P} \%$} & \multirow{2}{*}{ PIC } \\
\hline & & Min & Max & & & & & \\
\hline $\mathrm{CS} 1$ & $(\mathrm{CT})_{8} \mathrm{TG}$ & 250 & 1,000 & 11 & 0 & 11 & 100 & 0.2 \\
\hline $\mathrm{CS} 2$ & $(\mathrm{AC})_{8} \mathrm{YT}$ & 300 & 750 & 7 & 0 & 7 & 100 & 0.3 \\
\hline $\mathrm{CS} 3$ & $(\mathrm{AC})_{8} \mathrm{YG}$ & 150 & 1,000 & 15 & 0 & 15 & 100 & 0.3 \\
\hline CS4 & $(\mathrm{CT})_{8} \mathrm{RG}$ & 250 & 700 & 6 & 0 & 6 & 100 & 0.3 \\
\hline CS5 & $(\mathrm{GA})_{8} \mathrm{GT}$ & 200 & 900 & 11 & 3 & 8 & 72.7 & 0.3 \\
\hline CS6 & $(\mathrm{GA})_{8} \mathrm{~T}$ & 250 & 1,200 & 17 & 0 & 17 & 100 & 0.3 \\
\hline CS7 & $(\mathrm{GA})_{8} \mathrm{CT}$ & 350 & 1,400 & 13 & 0 & 13 & 100 & 0.2 \\
\hline $\mathrm{CS} 8$ & $(\mathrm{TC})_{8} \mathrm{AGT}$ & 300 & 1,000 & 15 & 0 & 15 & 100 & 0.3 \\
\hline CS9 & (TC) ${ }_{8} \mathrm{AGG}$ & 300 & 1,500 & 14 & 1 & 13 & 92.9 & 0.3 \\
\hline CS10 & $(\mathrm{AG})_{8} \mathrm{CTA}$ & 500 & 1,400 & 14 & 0 & 14 & 100 & 0.2 \\
\hline CS11 & $(\mathrm{AC})_{8} \mathrm{GA}$ & 280 & 1,600 & 21 & 0 & 21 & 100 & 0.3 \\
\hline $\mathrm{CS} 12$ & $(\mathrm{GA})_{8} \mathrm{C}$ & 250 & 850 & 14 & 1 & 13 & 92.9 & 0.2 \\
\hline Total & & & & 158 & 5 & 153 & $1,158.5$ & 3 \\
\hline Average & & & & 13.17 & 0.42 & 12.75 & 96.54 & 0.3 \\
\hline
\end{tabular}

${ }^{\mathrm{z}}$ ISSR: inter simple sequence repeat, Y: C/T, R: A/G, NTL: number of total loci, NM: number of monomorphic loci, NPL: number of polymorphic loci, P\%: polymorphism percentage, PIC: polymorphism information content. 

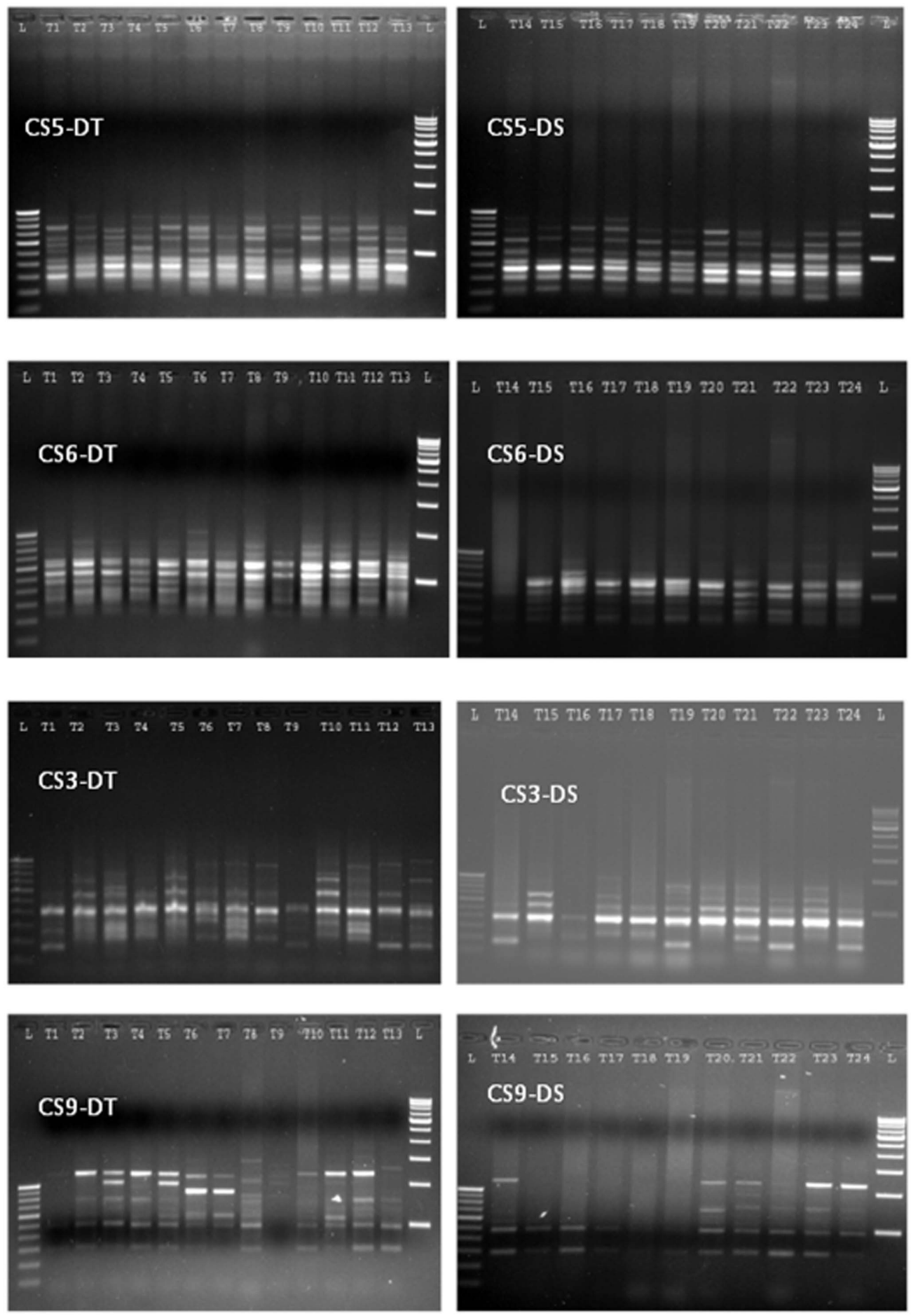

Fig. 4. Polymerase chain reaction amplification profiles generated by inter simple sequence repeat markers. CS: marker name, DT: drought tolerance, DS: drought susceptible.

both morpho-physiological traits and molecular markers is a more effective approach for selection of tolerant varieties. Morpho-physiological markers like leaf blade habit, pubescence, branch angle, leaf angle, WUE, transpiration rate, photosynthetic rate etc. are easily available traits for screening the germplasms. However in this study some 


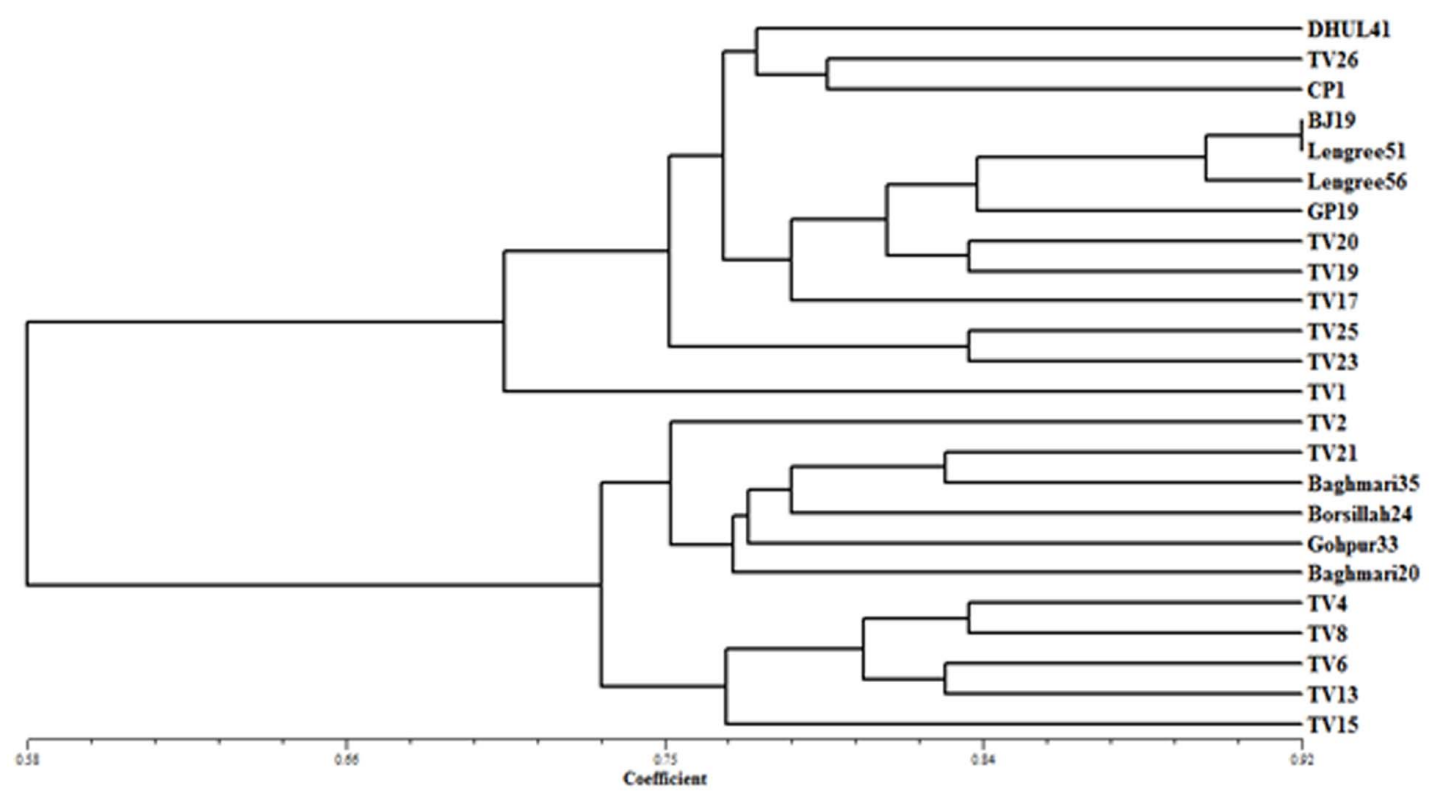

Fig. 5. Unweighted pair group method with arithmetic average dendrogram estimating genetic distances among 24 genotypes based on inter simple sequence repeat coefficient derived Jaccards matrix.

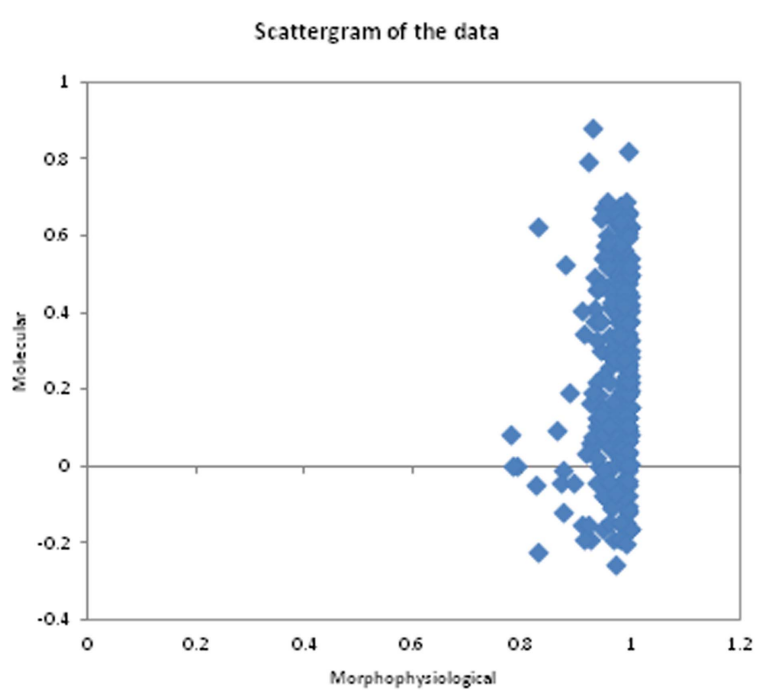

Fig. 6. Correlation between morpho-physiological traits and inter simple sequence repeat markers.

cultivars with drought traits are showing similar characteristics, but there are variations among the cultivars because of which morphophysiological studies could not group them into two distinct groups with drought contrasting traits. Some drought tolerant tea plants were found to have curved leaves whereas the susceptible plants were found to have expanded leaves. But there are exceptions among drought susceptible cultivars like Borshilla 24 and Baghmari 35 (Supplementary Table 2) which showed curved leaf blade habit. The adaptation in drought tolerant plants to have curved leaves is to have a smaller leaf area in order to decrease loss of water by evaporation and transpiration during the drought season. Water deficit was found to reduce leaf area in soyabean (Zhang et al. 2004), Populus (Wullschleger et al. 2005), Vigna unguiculata (Manivannan et al. 2007) and other plants (Farooq et al. 2009). Plants also reduce their leaf surface area by rolling or curling (Sheaffer and Moncada 2011). Drought-tolerant varieties in this study were found to have abundant tiny hairs called pubescence on the leaves and shoots than the susceptible ones. Pubescence has the property of reflecting light from the leaf surface and reduces leaf-surface temperature. These leaf structures can also reduce loss of moisture from the surface and help to preserve the much needed water during water stress (Konrad et al. 2015). Again varying branch angles, length of mature leaf petiole and leaf angle of stem with respect to petiole was observed among some of the drought tolerant and susceptible cultivars but the differences were not significant to group them into contrasting traits (Table 2). Drought tolerant clones like BJ19 and TV26 showed a varying branch angle 
of 56.66 and 37.5 respectively (Supplementary Table 2). Higher branch angle in tea will lead to a spreading bush architecture and leaf canopy, resulting in orientation of leaves towards horizontal. This will allow more incidence of sunlight, increasing the leaf temperature and higher transpiration loss. Increased incidence of solar radiation on leaves increase leaf-surface temperature and loss of moisture (Paparozzi 2008). Vertical leaf angles reduce the amount of light intercepted by the leaves. Again drought susceptible clones like Gohpur 33 and Baghmari 35 showed a varying leaf angle of 51.66 and 25 respectively indicated different morphological variations between cultivars of similar trait. Physiological parameters like mean photosynthetic rate was also not significant between the drought tolerant (12.9) and susceptible cultivars (12.4) (Table 2). Like other metabolic processes, photosynthesis also gets hampered due to unfavourable and stressful environments such as salinity, drought and high temperatures which induce a number of alterations in the physiological, biochemical and molecular processes of the plant. These factors contribute to a reduction in the photosynthetic rate of the plant by stress-induced stomatal or non-stomatal limitations (Ashraf and Harris 2013). Transpiration loss in plants accounts for $98 \%$ to $99 \%$ of the total water absorbed which mainly occurs through leaf surface by means of the stomata or cuticle. Regulating the loss of water through the cuticle or stomata is one of the survival means adopted by the plants to withstand during soil moisture deficit conditions under drought (Clarke et al. 1991). Soil moisture depletion affects the transpiration rates in tea leaves and the growth of the plant gets reduced when the available soil moisture level falls down a threshold limit. The studied drought tolerant clones were found to have less transpiration rates as compared to the drought susceptible ones which conform to the earlier reports of Wijeratne (1998) and Barman et al. (2008). Indicators for drought tolerance have often tended to focus on the use of higher WUE values as a physiological marker for drought tolerance. The WUE of a plant was determined from the ratio between $\mathrm{CO}_{2}$ assimilation rate and transpiration values. Higher WUE values provides an indication of drought tolerance. Varieties with high WUE values are able to assimilate more carbon and attain a more yield using lesser quantities of water than other varieties. Leaf surface waxiness and the cuticular wax content in this study were found to be significantly higher in the drought tolerant plants (Table 2). This study corroborates the findings of Barman et al. (2005). Drought tolerant plants are often found to accumulate wax on their leaf surfaces (Dimmit 2000). This morphological adaptation helps the plants to reduce moisture loss at times of water stress. Wax also reflects light from the leaf surface to help reduction in leaf temperature. Handique and Manivel (1990) also reported higher wax content in leaves of drought tolerant tea cultivars.

The 12 dinucleotide repeats markers studied could group the tea cultivars according to their drought tolerance or susceptibility indicating a strong positive association to the DNA sequences linked to drought. ISSR markers based on AG and GA repeats were reported to be highly informative in case of rice germplasms (Reddy et al. 2009). Charters et al. (1996) using three 5' anchored primers together could distinguish 20 cultivars of Brassica napus. Primer CS4 containing $(\mathrm{CT})_{8} \mathrm{RG}$ repeats revealed the highest PIC of 0.3 . PIC provides the value of a marker for detecting polymorphism introduced by Botstein et al. (1980). Chadha and Gopalakrishna (2007) reported PIC values of 0.1 to 0.5 in the study of genetic diversity using ISSR markers in rice. The highest of 0.4965 genetic diversity was observed within cultivars, based on Nei's gene diversity (Nei 1978). The total diversity of 0.3144 among the varieties over all loci indicated that there was a good genetic variation within and between the studied tea cultivars. The clustering of the 24 cultivars with drought contrasting traits into two groups with the 12 ISSR markers was found to be same as earlier evaluated through long term field trials in different agroclimatic conditions of North East India. Hence, these markers can be used to screen tea plants at a young stage in breeding programs for evaluating drought trait. Close clustering among the cultivars was expected as most of the germplasms originated from a common gene pool and this may be another factor for contributing towards similar type of characteristics. But clustering based on morphophysiological characters could not reflect the origin of the germplasms or the drought traits. The principal component analysis based on 
morphological and physiological analysis was unable to group the cultivar into two groups unlike the molecular markers. However, when only the important characteristics of morphology and physiological are taken into consideration they showed significant positive correlation with the molecular genetic distances. Positive correlation among datasets between molecular markers and morphophysiological traits were also reported for drought tolerant and sensitive cultivars of lentils (Singh et al.2016) and tall fescue (Sun et al. 2015). Therefore, morpho-physiological factors should be considered along with the molecular markers for selection of tea cultivars for improving the drought tolerance in tea.

This study indicates that a combination of significant morpho-physiological and molecular markers will be useful in studying genetic relationship of tea germplasms and also selecting better segregants with associated drought trait. Interestingly, the ISSR markers based on dinucleotide repeats could also significantly distinguish drought tolerant and susceptible cultivars into two different clusters. These ISSR markers may be used by tea breeders to classify tea germplasms into drought tolerant and susceptible categories to develop drought resistant cultivars. The markers used in this study will be useful to identify drought tolerant cultivars, maintain diverse genotypes, assess genetic diversity, pre-selection of seedling plants for drought resistant and to discard unfavourable genotypes at an early stage.

\section{ACKNOWLEDGEMENTS}

The authors acknowledge the support of Director Tea Research Association and DBT, Govt. of India for funding through their Biotech Hub programme.

\section{REFRENCES}

Ashraf M, Harris PJC. 2013. Photosynthesis under stressful environments: An overview. Photosynthetica 51: 163-190.

Barman TS. 2011. Choice of planting material for tea cultivation, p. 5-13. In: B.K. Goswami (ed.). Tea field management. Tea Research Association, Tocklai, Jorhat, India.

Barman TS, Baruah U, Saikia JK. 2008. Seasonal changes in metabolic activities of drought tolerant and susceptible clones of tea (Camelia sinensis L.). J. Plant. Crops. 36: 259-264.

Barman TS, Bhattacharrya N, Baruah U, Saikia JK. 2005. Water stress induced alteration of compatible osmolyte (proline) and wax in tea (Camellia sinensis L.) cultivars. Proc. of the: 2005 International Symposium on Innovation in Tea Science and Sustainable Development in Tea Industry. China Tea Science Society, Hangzhou, China. pp.769-795.

Botstein D, White RL, Skolnick M, Davis RW. 1980. Construction of a genetic linkage map in man using restriction fragment length polymorphisms. Am. J. Hum. Genet. 32: 314-331.

Chadha S, Gopalakrishna T. 2007. Comparative assessment of REMAP and ISSR marker assays for genetic polymorphism studies, in Magnaporthe grisea. Curr. Sci. 93: 688-692.

Charters YM, Robertson A, Wilkinson MJ, Ramsay G. 1996. PCR analysis of oilseed rape cultivars (Brassica napus L. ssp. oleifera) using 5'-anchored simple sequence repeat (SSR) primers. Theor. Appl. Genet. 92: 442-447.

Clarke JM, Richards RA, Condon AG. 1991. Effect of drought stress on residual transpiration and its relationship with water use of wheat. Can. J. Plant Sci. 71: 695-702.

Deshmukh R, Tomar NS, Tripathi N, Tiwari S. 2012. Identification of RAPD and ISSR markers for drought tolerance in wheat (Triticum aestivum L.). Physiol. Mol. Biol. Plants 18: 101-104.

Dimmit MA. 2000. Biomes and communities of the Sonoran desert region,. p. 3-18. In: S.J. Phillips, P.W. Comus (ed.). A natural history of the sonoran desert. Arizona-Sonora Desert Museum and University of California Press, Tucson, AZ.

Doyle JJ, Doyle JL. 1987. A rapid DNA isolation procedure for small quantities of fresh leaf tissue. Phytochem. Bull. 19: 11-15.

Farooq M, Wahid A, Kobayashi N, Fujita D, Basra SMA. 2009. Plant drought stress: Effects, mechanisms and management. Agron. Sustain. Dev. 29: 185-212.

Gogoi M, Zaman A, Das S, Singh HR, Bhagawati P, Chowdhury $\mathrm{P}$, et al. 2014. In silico identification and 
functional annotation of SSR-ESTs related to drought and herbivory in Camellia sinensis var assamica. Two Bud. 60: 43-50.

Handique AC, Manivel L. 1990. Effect of certain antitranspirant in tea (Camellia sinensis L.). Two Bud. 37: 20-23.

IPGRI (International Plant Genetic Resources Institute). 1997. Descriptors for tea (Camellia sinensis). International Plant Genetic Resources Institute, Rome, Italy.

Konrad W, Burkhardt J, Ebner M, Roth-Nebelsick A. 2015. Leaf pubescence as a possibility to increase water use efficiency by promoting condensation. Ecohydrology 8: 480-492.

Liu K, Muse SV. 2005. PowerMarker: An integrated analysis environment for genetic marker data. Bioinformatics 21: 2128-2129.

Manivannan P, Abdul Jaleel C, Kishorekumar A, Sankar B, Somasundaram R, Sridharan R, et al. 2007. Changes in antioxidant metabolism of Vigna unguiculata (L.) Walp. by propiconazole under water deficit stress. Colloids Surf. B. Biointerfaces 57: 69-74.

Nei M. 1978. Estimation of average heterozygosity and genetic distance from a small number of individuals. Genetics 89: 583-590.

Panda H. 2011. The complete book on cultivation and manufacture of tea. Asia Pacific Business Press Inc., New Delhi, India.

Paparozzi ET. 2008. Anatomical and physiological changes that occur during rooting of cuttings, p. 189-194. In: C.A. Beyl, R.N. Trigiano (ed.). Plant propagation concepts and laboratory exercises. CRC Press, Boca Raton, FL.

Reddy ChS, Babu AP, Swamy BP, Kaladhar K, Sarla N. 2009. ISSR markers based on GA and AG repeats reveal genetic relationship among rice varieties tolerant to drought, flood, or salinity. J. Zhejiang Univ. Sci. B. 10: 133-141.

Ribas-Carbo M, Taylor NL, Giles L, Busquets S, Finnegan PM, Day DA, et al. 2005. Effects of water stress on respiration in soybean leaves. Plant Physiol. 139: 466-473.

Sarla N, Bobba S, Siddiq EA. 2003. ISSR and SSR markers based on AG and GA repeats delineate geographically diverse Oryza nivara accessions and reveal rare alleles. Curr. Sci. 84: 683-690.

Sheaffer CC, Moncada KM. 2011. Introduction to agronomy: Food, crops, and environment. Delmar Cengage Learning, Clifton Park, NY.

Silva Fernandes AM, Baker EA, Martin JT. 1964. Studies on the plant cuticle: VI. The isolation and fractionation of cuticular waxes. Ann. Appl. Biol. 53: 43-58.

Singh ID. 2006. Selection and testing field performance of candidate tea clones in India. IJTS 5: 1-12.

Singh D, Singh CK, Tomar RS, Taunk J, Singh R, Maurya S, et al. 2016. Molecular assortment of lens species with different adaptations to drought conditions using SSR markers. PLoS ONE 11: e0147213.

Smith JSC, Smith OS. 1992. Fingerprinting crop varieties. Adv. Agron. 47: 85-140.

Sun X, Xie Y, Bi Y, Liu J, Amombo E, Hu T, et al. 2015. Comparative study of diversity based on heat tolerantrelated morpho-physiological traits and molecular markers in tall fescue accessions. Sci. Rep. 5: 18213.

Tomar RS, Parakhia MV, Patel SV, Golakiya BA. 2010. Molecular markers and plant biotechnology. New India Publishing Agency, New Delhi, India.

Wijeratne MA, Fordham R, Anandacumaraswamy A. 1998. Water relations of clonal tea (Camellia sinensis L.) with reference to drought resistance: II. Effect of water stress. Trop. Agric. Res. Ext. 1: 74-80.

Wullschleger SD, Yin TM, DiFazio SP, Tschaplinski TJ, Gunter LE, Davis MF, et al. 2005. Phenotypic variation in growth and biomass distribution for two advancedgeneration pedigrees of hybrid poplar. Can. J. For. Res. 35: 1779-1789.

Zhang WK, Wang YJ, Luo GZ, Zhang JS, He CY, Wu XL, et al. 2004. QTL mapping of ten agronomic traits on the soyabean (Glycine max L. Merr.) genetic map and their association with EST markers. Theor. Appl. Genet. 108: 1131-1139. 